\title{
The use of non-prion biomarkers for the diagnosis of Transmissible Spongiform Encephalopathies in the live animal
}

\author{
Ifat PARVEEN $^{\mathrm{a} *}$, Jon MOORBY ${ }^{\mathrm{a}}$, Gordon ALLISON ${ }^{\mathrm{a}}$, Roy JACKMAN ${ }^{\mathrm{b}}$ \\ a Institute of Grassland and Environmental Research, Plas Gogerddan, Aberystwyth, \\ SY23 3EB, United Kingdom \\ b Veterinary Laboratories Agency, New Haw, Addlestone, Surrey, KT15 3NB, United Kingdom
}

(Received 1 December 2004; accepted 28 February 2005)

\begin{abstract}
Scrapie and bovine spongiform encephalopathy (BSE) are major global concerns and the emergence of variant Creutzfeldt-Jakob disease ( $\mathrm{VCJD}$ ) has caused turmoil for blood transfusion services and hospitals worldwide. Recent reports of iatrogenic CJD (iCJD) cases following blood transfusions from Transmissible Spongiform Encephalopathies (TSE)-infected donors have fuelled this concern. Major diagnostic tests for BSE and scrapie are conducted post-mortem from animals in late stages of the disease. Although the lymphoreticular system is involved in the earlier pathogenesis of some forms of sheep scrapie and VCJD, which presents great opportunity for diagnostic development, other TSE diseases (some strains of scrapie, sporadic CJD (sCJD) and bovine BSE) do not present such a diagnostic opportunity. Thus, there is an urgent need for premortem tests that differentiate between healthy and diseased individuals at early stages of illness, in accessible samples such as blood and urine using less invasive procedures. This review reports on the current state of progress in the development and use of prion and non-prion biomarkers in the diagnosis of TSE diseases. Some of these efforts have concentrated on improving the sensitivity of $\mathrm{PrP}^{\mathrm{Sc}}$ detection to allow in vivo diagnosis at low abundances of $\mathrm{PrP}^{\mathrm{Sc}}$ whilst others have sought to identify non-prion protein biomarkers of TSE disease, many of which are still at early stages of development. In this review we comment upon the limitations of prion based tests and review current research on the development of tests for TSE that rely on non-prion disease markers in body fluids that may allow preclinical disease diagnosis.
\end{abstract}

BSE / scrapie / vCJD / diagnostic / non-prion markers

Table of contents

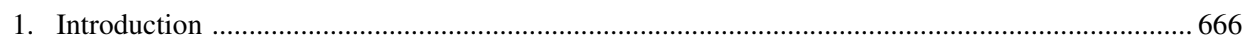

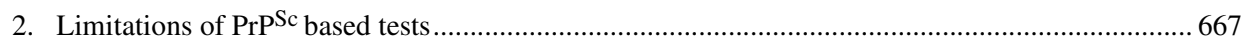

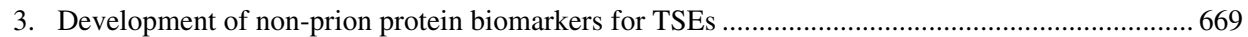

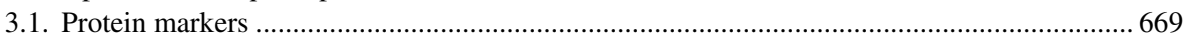

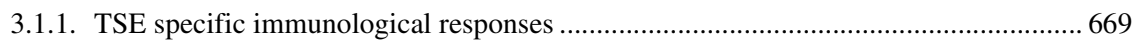

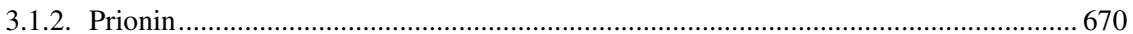

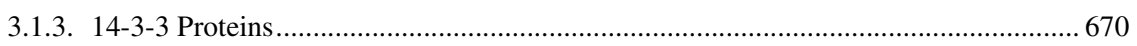

* Corresponding author: ifat.parveen@bbsrc.ac.uk 
3.1.4. Neurone specific enolase......

3.1.5. S100B proteins and glial fibrilliary acidic proteins.

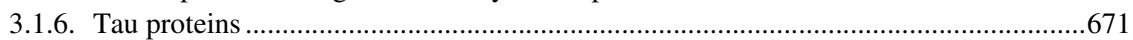

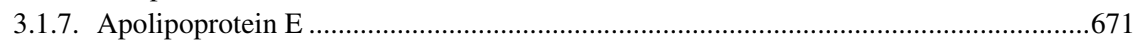

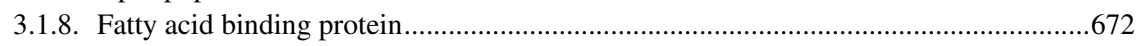

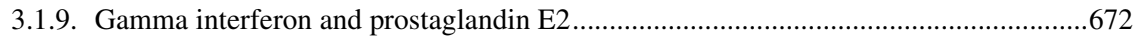

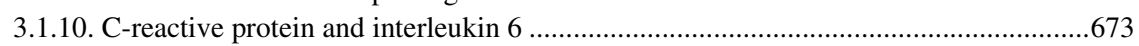

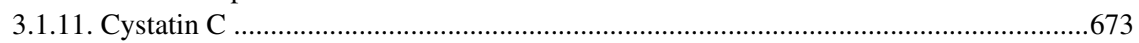

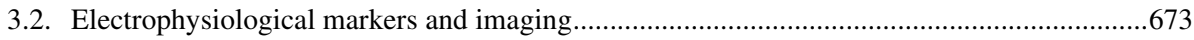

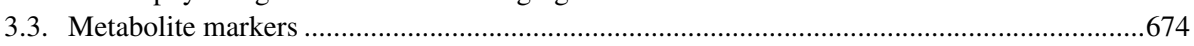

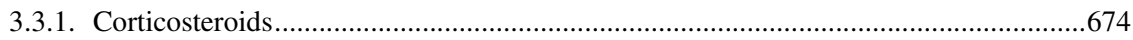

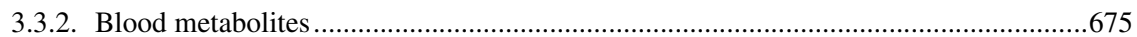

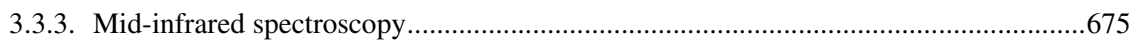

3.4. Transcriptional markers: erythroid differentiation-related factor ...................................676

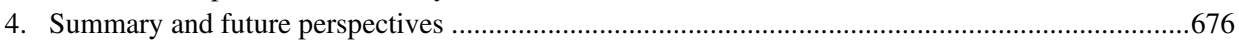

\section{INTRODUCTION}

Transmissible spongiform encephalopathies (TSE) are a family of diseases which include Bovine Spongiform Encephalopathy (BSE) in cattle, scrapie in sheep, and Creutzfeldt-Jakob disease (CJD) in humans [89]. Characteristics of these degenerative disorders of the central nervous system (CNS) include the accumulation of abnormal prion proteins $\left(\mathrm{PrP}^{\mathrm{Sc}}\right)$, neuronal cell loss, vacuolation of specific areas of the brain and astrocytic gliosis and amyloid deposition [89, 90]. Disease specific prion proteins are present in a range of tissues but predominantly in the brain tissue and spinal cord at terminal stages of disease. In some TSEs, lymph node follicles and gut associated lymphoid tissue may also present with pathognomonic $\mathrm{PrPSc}^{\mathrm{Sc}}$ accumulations during disease pathogenesis and there are indications that some circulating leucocytes may also be associated with infectivity [49]. The physiological function of the prion proteins is still unclear; however, it is known that in the $\alpha$-helix form prion proteins are soluble and easily degraded, whereas in the $\beta$-form, they are insoluble and resistant to degradation [89]. The onset of TSE diseases involves conversion of the normal cellular prion protein $\left(\mathrm{PrPC}^{\mathrm{C}}\right)$ into the abnormal disease causing isoform $\left(\mathrm{PrPSc}^{\mathrm{S}}\right)$, which involves a conformational change from an $\alpha$-helix to a $\beta$-sheet $[46,79,124]$. In the abnormal form $\left(\mathrm{PrPSc}^{\mathrm{Sc}}\right)$ the protein has the potential to convert $\operatorname{PrPC}^{\mathrm{C}}$ molecules into the infectious, $\mathrm{PrPSc}^{\mathrm{S}}$ form thus replicating the agent. Lifethreatening pathological changes and clinical disease, however, only follow neuroinvasion by the $\mathrm{PrPSc}$.

Scrapie (sheep and goats), BSE (cattle), chronic wasting disease (elk and deer), feline spongiform encephalopathy (FSE; cats), sporadic, new variant, iatrogenic CJD and Kuru (humans) are all transmissible spongiform encephalopathies (TSEs), i.e. prion diseases that can be transmitted from one host to another [88, 89], although not necessarily by contact or association. Two other lesser-known TSE diseases also affect humans and are inherited from one generation to another. These are GerstmannSträussler-Scheinker syndrome (GSS) and fatal familial insomnia (FFI) [89, 90]. Scrapie was first reported in 1732 and BSE was first identified in 1986. Both have had major agricultural and economic impacts in Western Europe and the USA [3, 24]. The high prevalence of BSE in the United Kingdom is thought to have resulted from the inclusion of meat and bone meal produced from inappropriately rendered ruminant carcasses in ruminant feeds and since 1988 , the use of meat and bone meal in animal 
feeds (sheep and cattle) has been banned in the UK [3, 88, 89]. The first case of variant CJD (vCJD), a disease of humans typically aged between 17-50 years, was reported in 1996 [123] and soon after it was proposed that vCJD was linked with BSE and likely to be due to consumption of beef contaminated with infectious material during the late 1980s and early 1990s. Recently, concerns have intensified over the iatrogenic spread of vCJD as a small, but growing number of iatrogenic CJD (iCJD) cases have resulted from surgical or medicinal contaminations derived from TSE-infected donors [50, 81].

The principle route of BSE infection is apparently oral, and although the exact nature of the route of infection of scrapie is unclear, it also is assumed to be primarily oral; similarly Kuru, a TSE disease of the Fore people in New Guinea whereby prions were transmitted through ritualistic cannibalism $[88,89]$ has an oral route of infection. The precise tissue distribution of $\mathrm{PrPSc}^{\mathrm{Sc}}$ and the location of lesions is characteristic for different TSE diseases. In naturally occurring cases of BSE in cattle, infectivity is barely detectable outside the central nervous system, which may prove problematic in the development of preclinical diagnostics. In contrast, sheep deliberately challenged with BSE display $\mathrm{PrPSc}^{\mathrm{Sc}}$ in a broad range of tissues including the lymphoid system, parts of the digestive tract and in the peripheral nervous system [29]. The distribution of infectivity in these BSE affected sheep is similar to that observed in sheep of similar PrP-genotype infected with scrapie $[9,42,62,63]$. The spread of $\mathrm{PrP}^{\mathrm{Sc}}$ to the lymphoid organs is thought to be mediated by the lymphoreticular system. Studies have shown that the eventual transport of $\mathrm{PrPSc}^{\mathrm{S}}$ to the CNS is mediated by axonal transport within the parasympathetic and the sympathetic nervous system $[4,62,63$, 109, 115, 116].

The outbreaks of BSE and VCJD - in the UK and worldwide [14, 35, 53, 104] - has prompted the development of rapid, relia- ble and inexpensive screening methods that allow TSEs to be identified at both symptomatic and pre-symptomatic stages in live animals. The incubation period of TSEs in animals can typically take up to 5 or more years, although a shorter incubation period of 1 to 2 years is often observed in sheep with scrapie-sensitive PrP genotype and it is evident that there is a real risk of preclinical, infected animals entering the human food chain. None of the $\mathrm{PrPSc}^{\mathrm{S}}$ - based tests that are currently available commercially are entirely suitable for preclinical diagnosis on a large scale being either too insensitive or targeted at tissues unaffected by $\mathrm{PrPSc}^{\mathrm{S}}$ accumulation during the preclinical incubation period. The aim of this paper is to report on the current state of knowledge in the development and use of non-prion biomarkers in the diagnosis of preclinical TSE diseases. The focus of this review is primarily BSE, scrapie and VCJD as many of the diagnostics developed to date have concentrated on these TSE diseases.

\section{LIMITATIONS OF PRPSc BASED TESTS}

Confirmation of a TSE disease is carried out post-mortem by the observation of characteristic vacuolar or spongiform changes in specific areas of the brain by histopathological examination of fixed brain sections under light microscopy. In effect, all confirmatory and screening-based diagnostics are dependent on the detection of disease-

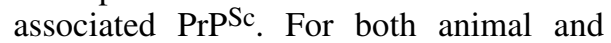
human TSEs, the localisation of $\mathrm{PrPSc}^{\mathrm{Se}}$ deposits at morphologically defined sites by immunohistochemistry (IHC) is also used to confirm disease at clinical endpoint. However, both these confirmatory tests require the expert interpretation of a trained pathologist and are not appropriate for widespread screening use.

Prion infectivity bioassays remain as one of the most sensitive methods for detecting TSEs and are also used for confirmation as 
they fulfil the "transmissibility requirement" for classification of a neurological disease as being a TSE. Inevitably, bioassays are limited in scope because of the time taken for disease to develop in the test animal (usually rodents) and in some instances there are major limitations due to cross species barrier effects on transmission. Recent developments include transgenic mice expressing high levels of bovine prion protein, but not expressing murine prion protein. These mice are highly sensitive to infection with BSE and have relatively short but still significant incubation periods; their use has greatly facilitated detecting BSE [58].

The most widely used TSE diagnostics for animal testing rely on immunological detection (by immunoassay - or by polyacrylamide gel electrophoresis followed by Western immunoblotting) of $\mathrm{PrP}^{\mathrm{Sc}}$ following extensive proteolysis with proteinase $\mathrm{K}$. Protease treatment of every sample is essential for the elimination of all $\mathrm{PrPC}^{\mathrm{C}}$ because until recently there are no effective diagnostic immunoreagents capable of differentiating $\mathrm{PrP}^{\mathrm{C}}$ from $\mathrm{PrP}^{\mathrm{Sc}}$. However, although essential for specificity, it is generally agreed that proteolytic digestion increases the complexity of the assay and may limit its sensitivity. Although such tests are currently widely used, they are expensive and time-consuming and not easily automated or standardised for routine large-scale diagnostic screening.

Post-mortem BSE diagnostic tests approved by the European Commission (EC) in 1999, include the Prionics-Check Western (Prionics AG, Schlieren, Switzerland) [58, 101], Enfer (Enfer Scientific Ltd., Tipperary, Ireland) [13, 72] and BioRad TeSeE or Platelia (Bio-Rad Laboratories Ltd., Hemel Hempstead, UK) [13, 58, 72]. The Prionics-Check LIA (Prionics AG) [58] and the Inpro conformation-dependent immunoassay (CDI; InPro Biotechnology,
Inc., San Francisco, USA) [98] have been positively evaluated by the EC for postmortem diagnosis of BSE in cattle in 2003. The CDI immunoassay advances the search for conformational specificity by subtracting signal generated by $\mathrm{PrP}^{\mathrm{C}}$ from that obtained for total $\left(\mathrm{PrPC}^{\mathrm{C}}+\mathrm{PrPSc}^{\mathrm{S}}\right)$ prion protein. Recently, the European Food Safety Authority (EFSA) published a report in which they recommend seven new tests for approval by the EC. These tests include: IDEXX Herd Chek (IDEXX Laboratories Inc., Westbrook, Maine, USA) ${ }^{1}$, CediTect BSE (Cedi Diagnostics, Lelystad, the Netherlands), Speed'it BSE (Institut Pourquier, Montpellier, France), Prionics-Check PrioSTRIP (Prionics, Schlieren, Switzerland), Roboscreen BSE post-mortem kit (Roboscreen, Leipzig, Germany), PrionScreen (Roche Diagnostics, Penzberg, Germany) and the Enfer TSE (Abbott Laboratories, Abbott Park, Illinois, USA). All these tests have been evaluated for the analysis of bovine brain for BSE. The IDEXX system is the first to employ a $\mathrm{PrP}^{\mathrm{Sc}}$ specific ligand which considerably reduces assay time and complexity. At present, the most widely used BSE diagnostic tests in Europe are the PrionicsCheck Western and Platelia tests which have both been reported to be $100 \%$ sensitive and $100 \%$ specific by the EU evaluation process [69].

Prevention of TSE transmission and isolation of infected animals are major global concerns. Pre-mortem tests which could detect early infection would reduce the risk of infected (but not clinically ill) animals entering the food chain and cosmetic and health care products, prevent unnecessary slaughter of healthy animals, reduce the risk of transmission of TSE between animal species and allow for an accurate prediction of a TSE epidemic (i.e. BSE, vCJD). Furthermore, such tests would help reduce the risk of transmission of vCJD from human to human via blood or blood products and

\footnotetext{
${ }^{1}$ EFSA Scientific Report 18, 1-13, on the Evaluation of Seven New Rapid post mortem BSE Tests, Question No EFA-Q-2003-084 [on line] (2004) http://www.efsa.eu.int/science/tse_assessments/bse_tse/694/ sreport18_7new_rpmt_bse_en1.pdf [consulted on 3 February 2005].
} 
improve our understanding of prion diseases potentially aiding the development of effective therapies for TSE patients. One of the major challenges in the development of pre-mortem tests is that they must be applicable to accessible samples such as blood or urine and be sensitive enough to detect low concentrations of disease specific markers. This poses a major problem as the prion proteins in the blood and urine of TSE infected subjects are at much lower concentrations than in the brain tissue and CNS $[17,18]$ and in many cases may not be present at all. Whilst these difficulties have led many researchers to look for alternative, surrogate disease markers there is still considerable activity in developing new $\mathrm{PrPSc}^{\mathrm{Sc}}$ based methods. These exploit physiochemical differences between the abnormal and normal forms of the prion protein in order to detect PrPSc in blood. Chief amongst these approaches are capillary immunoelectrophoresis assay with fluorescent labelled peptides [105], sandwich conformation dependant immunoassay (CDI) [12], ligand based immunoassay (Microsens) ${ }^{2}$, RNA aptamer technology (Vitex) [100] and a blood-based antibody test for vCJD and BSE (Caprion Pharmaceuticals Inc. in collaboration with Ortho-Clinical Diagnostics and IDEXX Laboratories Inc.) [97]. At the time of writing, none of these have proved successful in routine use and all may be restricted to use in animals known to carry infectivity in blood [47, 49].

A potentially useful preclinical prion diagnostic test for urine samples was reported by Shaked et al. [108] who demonstrated the presence of a proteinase $\mathrm{K}$ (PK)-resistant protein band of approximately $32 \mathrm{kDa}$ in the urine of scrapie infected hamsters, BSE infected cattle and CJD patients, which they thought to be $\mathrm{PrPSc}^{\mathrm{Sc}}$. However, a more recent study by Furukawa et al. [31] reported that the signal observed by Shaked et al. [108] was absent in the urine of TSE infected humans, but discrete protein bands of molecular weight $\sim 37 \mathrm{kDa}$ were detected and proposed that these bands were outer membrane proteins (OMPs) resulting from bacterial contamination.

\section{DEVELOPMENT OF NON-PRION PROTEIN BIOMARKERS FOR TSES}

This area has expanded recently due to advances in post-genomic technologies which have provided new methods for identifying novel biomarkers. It is now possible to compare total gene expression at the transcriptome, proteome or metabolome level in the tissue or blood of TSE infected subjects at various time points during disease progression. These approaches have identified several non-prion protein biomarkers as indicators of the onset of TSE disease.

\subsection{Protein markers}

\subsubsection{TSE specific immunological responses}

The presence of disease specific antibodies in the blood and tissues of infected individuals is commonly used to diagnose disease but this approach has been unsuccessful for TSE diseases. The detection of anti PrPSc antibodies in blood samples would appear an ideal approach to diagnose TSE diseases in living animals. However, there have been many efforts to detect specific immunological responses to TSEs since the first reported attempt to detect anti-scrapie fibril antibodies in infected sheep in 1959 [22] but these have all resulted in failure (reviewed by Brown, 1990 [16]). It is now generally accepted that prion proteins are poor immunogens and hence the lack of a detectable immune response to both the cellular and the disease associated form of the PrP protein [43].

\footnotetext{
2 First demonstration of CJD detection in human blood [on line] (2004) http://212.67.202.140/ biotech/ News/London/microsens.htm [consulted on 23 June 2004].
} 


\subsubsection{Prionin}

Prionin proteins, so named because of their close genetic relationship to the prion protein genes, are thought to be induced in TSE diseases and are mainly found in the peripheral tissues; they are thought to be transported alongside $\mathrm{PrPSc}^{\mathrm{Sc}}$ to the brain [97]. It has been suggested that prionin proteins are expressed in the early stages of the disease; they have been detected in the blood of humans infected with CJD, cattle with BSE and in sheep with scrapie. Except in mice, prionin proteins are comprised of four or five equally spaced $\beta$-sheets and it has been proposed that these interact with $\mathrm{PrP}^{\mathrm{C}}$ and participate in their conversion to $\mathrm{PrPSc}^{3}$. It is also reported that expression of prionins in subjects results in the expression of specific anti-prionin endogenous antibodies and Altegen Inc. have exploited this to develop a blood-based TSE ELISA test to detect anti-prionin antibodies ${ }^{3,4}$. It is claimed that the Altegen test is able to detect endogenous anti-bovine, anti-scrapie and anti-CJD prionin antibodies in as little as 1-2 $\mu \mathrm{L}$ serum and results are obtained within $3 \mathrm{~h}$. The test reportedly indicates TSE infection 2-3 years post infection and is highly sensitive and specific in all premortem subjects. Interestingly, prionin proteins have also been reported to be expressed in Alzheimer's patients and in breast cancer [97], diseases that share some pathological features with TSEs.

\subsubsection{4-3-3 Proteins}

In 1986 two proteins were identified in the cerebrospinal fluid (CSF) of patients with sporadic CJD (sCJD), which were later demonstrated to belong to the 14-3-3 family of brain proteins. This group of acidic proteins are expressed in all Eukaryotes and modulate the activity of many cellular com- ponents and cellular processes including protein trafficking and cell cycling primarily by modulation of kinase induction pathways. Their appearance in CSF is thought to be associated with neuronal disruption in the brain. 14-3-3 protein accumulation is highly indicative of sCJD and this disease is detected with a specificity of $92 \%$ and a sensitivity of $96 \%$ [38] by this approach. However, this protein is a poor marker of vCJD $(50 \%$ of patients with confirmed vCJD and $9 \%$ of controls cases) [38], but is used as one of the differentiation parameters for these two forms of human TSE. 143-3 protein also appears in the CSF of sheep with scrapie and cattle with BSE and has been investigated extensively as a diagnostic marker of TSEs in these species [61, 95, 113]. However, the results have been disappointing as the 14-3-3 levels in infected sheep and cattle were not significantly different to the control animals therefore, it seems unlikely that 14-3-3 protein will be useful as a diagnostic aid for scrapie and BSE [95, 97, 113].

\subsubsection{Neurone specific enolase}

The neurone specific enolase (NSE) isoform (2-phospho-d-glycerol hydrolase) from human neurone and neuroendocrinal cells has been investigated as a possible surrogate marker of CJD disease progression. This protein is elevated in the CSF of patients suffering from stroke, haemorrhage and hypoxic brain damage [73]. Scientific evidence supports an elevation of NSE in the CSF of CJD subjects but it is unclear whether NSE could be used as a useful diagnostic marker [2]. NSE is also present in human serum, but the same study found no significant differences in the NSE concentrations observed in serum of CJD subjects and their controls [130].

\footnotetext{
${ }^{3}$ Prionin Protein Detection [on line] http://www.altegen.com/cliedit.htm [consulted on 3 June 2004].

${ }^{4}$ Technologies (BSE PLUS-test) [on line] http://www.altegen.com/bseplus.htm [consulted on 21 June 2004].
} 


\subsubsection{S100B proteins and glial fibrilliary acidic proteins}

An acidic calcium binding protein, S100B, is produced by astrocytes, microglial cells and oligodendroglial cells. Several studies have reported increased abundances of S100B in CSF from patients afflicted with sporadic and variant CJD [7, $40,74]$ and preclinical Alzheimer's disease (AD) [73]. In cattle CSF, S100B levels were significantly elevated in confirmed field cases of BSE when compared to clinically normal controls and to BSE-suspect animals later confirmed as BSE negative by histopathology [39]. Concentrations of S100B in serum from CJD patients were significantly higher than in control human sera or sera from patients with other dementias and the authors reported a diagnostic sensitivity of $78 \%$ and specificity of $81 \%$ [77]. The results of this study also indicated that elevation of serum S100B occurred in humans before clinical signs of CJD were fully apparent. However, studies with hamsters infected with scrapie have cast doubt on these promising results. In hamsters, serum levels of S100B become elevated only towards the end of scrapie progression $[11,76]$ suggesting that S100B may not be useful as a general preclinical TSE diagnostic marker [11]. Studies of S100B in serum from cattle with BSE have also been disappointing [39, 94]. Furthermore, it has been demonstrated that inappropriate handling, transportation and storage of blood samples taken from field cases increases the apparent abundance of S100B in serum as multimeric S100B complexes undergo a limited proteolysis, which increases the abundance of dimeric S100B [73].

Glial fibrilliary acidic proteins (GFAP) are constituents of intermediate filaments in astrocytes and concentrations are elevated during astroglial activation. Concentrations of GFAP are elevated in patients suffering from several diseases including $\mathrm{AD}$ and vascular dementia $[30,117]$. The proteins are expressed in the brain in various animal models of TSE soon after infec- tion, before clinical signs of the disease are apparent [93]. In addition, in the animal model, GFAP mRNA levels are elevated tenfold in infected mice brains in comparison to controls [57, 60]. However, sensitive techniques for GFAP detection have failed to show significant differences between GFAP protein levels in sera from CJD infected and control patients [66,73].

\subsubsection{Tau proteins}

Tau proteins are microtubule-associated proteins found in the CNS and in axons that are involved in many neurodegenerative disorders including Alzheimer's disease. Furthermore, increased concentrations of Tau proteins $(300 \mathrm{pg} / \mathrm{mL}$ to $900 \mathrm{pg} / \mathrm{mL})$ have been reported in CSF of patients with AD. Using a commercially available ELISA kit, levels of total Tau protein have been determined in CSF from CJD. Results indicate that as a diagnostic marker of CJD, Tau protein is comparable with 14-3-3 protein detection [75, 78]. In addition, Tau protein analysis may be useful for diagnosis of other human TSEs. Concentrations of total Tau protein are often elevated in CSF from patients with vCJD [40] and some research suggests that dementia specific changes in Tau protein phosphorylation have been observed [51, 114].

\subsubsection{Apolipoprotein E}

Several studies have reported the involvement of apolipoprotein E (ApoE) with TSE disease progression. ApoE is the major component of the very low density lipoproteins (VLDL), which act to remove excess cholesterol from the blood and transport it to the liver for processing. The role of ApoE in the nervous system remains unclear but it is thought to be involved in nerve growth, regeneration and neuronal repair $[44,45]$. ApoE concentrations have been shown to be elevated in the brains of scrapie infected mice and has been detected in some prion protein deposits [26, 27]. Using 2-D gel electrophoresis, Jones et al. 
[52] demonstrated $100 \%$ specificity and sensitivity for raised ApoE levels in BSE affected cattle but this approach to diagnosis was not followed up by this group. However, similar findings were reported by Hochstrasser et al. [44]. Choe et al. [23] recently demonstrated increased concentrations of ApoE in the CSF of vCJD patients but not patients with sCJD.

Further studies need to be conducted to establish the earliest point at which ApoE concentrations become elevated in TSE disease before its usefulness as a diagnostic marker can be determined. Proteome Sciences (Surrey, UK) are currently investigating ApoE as a preclinical surrogate marker for BSE in blood.

\subsubsection{Fatty acid binding protein}

A recent study by Guillaume et al. [41] identified the heart fatty acid binding protein (H-FABP) family as a potential marker of CJD. Fatty acid binding proteins are small, highly conserved cytosolic proteins that are involved in fatty acid transport and metabolism. The authors used 2D-electrophoresis and matrix-assisted laser desorption/ionisation-time of flight (MALDI-TOF) mass spectroscopy to show that concentrations of H-FABP are often elevated in CSF and plasma from patients with vCJD in comparison to samples taken from healthy control patients and from patients suffering from other neurodegenerative disorders. However, the specificity and sensitivity of $\mathrm{H}-\mathrm{FABP}$ concentration elevation and protein estimation are insufficient for this marker to be used for diagnosis of vCJD without the support of other diagnostic tests.

\subsubsection{Gamma interferon and prostaglandin $\mathrm{E} 2$}

Gamma interferon (IFN- $\gamma$ ) is a type II immune-response interferon that has been implicated as a marker of TSE disease. The function of IFN- $\gamma$ is well documented and includes induction of antiviral states and modulation of immune response [102] in diseases including listeria [6, 96], Mycobacterium bovis infection $[25,71,121]$ and bovine herpes [37]. Murphy et al. [70] reported that plasma concentrations of IFN- $\gamma$ in field cases of BSE suspect cattle were significantly increased above controls. However, subsequent testing by post-mortem histopathological examination showed some of these animals to be BSE negative despite their elevated plasma concentrations of IFN- $\gamma$, consequently the diagnostic importance of IFN- $\gamma$ remains unresolved.

Prostaglandin $\mathrm{E}_{2}\left(\mathrm{PGE}_{2}\right)$ is a hormone involved in a wide range of physiological processes [70] including cell activation and regulation [80]. Mingetti et al. [65] found increased brain synthesis of $\mathrm{PGE}_{2}$ in human patients with sporadic and familial CJD and in scrapie infected mice. However, data from field cases of suspected BSE were difficult to interpret as several of these suspect cases were subsequently diagnosed as BSE negative despite having elevated levels of serum $\mathrm{PGE}_{2}$. These studies demonstrate the difficulties associated with the use of surrogate markers downstream of the primary disease locus or when changes can occur as a result of multiple physiological responses.

In 2000, Boehringer Ingelheim's animal health division filed for a patent on a preclinical and clinical test to detect BSE in live animals that is based upon measuring abnormal levels of marker proteins such as laminin receptor (LR), laminin receptor precursor (LRP) and IFN- $\gamma$ in the blood of infected animals. Studies [34, 92] have indicated that LR/ LRP may have a role in susceptibility to oral TSE infection, but there is no substantial evidence to suggest that they are surrogate markers of TSE diseases. Other studies have shown specific interactions between PrP and LRP [32, 48]. Boehringer Ingelheim reports to have developed antibodies and oligonucleotides specific to the marker proteins and their mRNAs. However, to date, no further work has been reported on the development of a preclinical blood based test for these postulated marker proteins. 


\subsubsection{C-reactive protein and interleukin 6}

A number of authors have reported abnormal concentrations of specific plasma proteins apparently caused by neuronal loss and tissue damage during the pre-symptomatic phase of TSE infection. Völkel et al. [120] recently identified two potential markers, C-reactive protein (CRP) and interleukin 6 (IL-6) in the plasma of sporadic CJD subjects. Expression of CRP and IL-6 in CJD patients were compared to proteins S100 and NSE which have previously been reported as markers of CJD in human plasma [77, 91, 119]. According to Völkel et al. [120], CRP identified $78.3 \%$ of a group of 46 subjects with SCJD as positive for the disease, while IL-6 identified 73.3\%, and NSE and S100 identified 13\% and $76.1 \%$ of the patients respectively. These results indicate that $\mathrm{CJD}$ gives rise to $\mathrm{CRP}$, IL-6 and S100 in blood plasma as a consequence of neuronal and tissue damage during CJD. However, whether the increased levels are specific to TSE infection remains to be determined. Furthermore, current methods of detection for these proteins are insufficiently sensitive for them to be used as indicators of preclinical TSE disease.

\subsubsection{Cystatin C}

Recently, the potent protease inhibitor cystatin $\mathrm{C}$ has been suggested as a marker of prion disease [99]. Increased concentrations of the protein have been reported in the CSF of CJD patients [99]. Cystatin C is a low molecular weight, non-glycosylated protein produced by nucleated cells; it is localised in glial cells and neurons and mostly abundant in the CSF. The protein has been affiliated with brain injury and elevated levels in response to cellular damage have been reported [99]. In humans, the protein is thought to be associated with cerebral amyloid angiopathy and reported to be co-localised with amyloid $\beta$ protein in $\mathrm{AD}$, in which increased levels of the protein in the CSF have been documented [21, 99, 127]. Using surface-enhanced laser desorp- tion/ionisation-time of flight (SELDI-TOF), sodium dodecyl sulphate-polyacrylamide gel electrophoresis (SDS-PAGE) and liquid chromatography-tandem mass spectrometry (LC-MS/MS), Sanchez et al. [99] demonstrated raised cystatin $\mathrm{C}$ levels in the CSF of CJD-infected patients. This study suggests an involvement of cystatin $\mathrm{C}$ in cerebral amyloidoses and neurodegenerative processes and needs to be investigated further to be considered as a pre-mortem diagnostic marker of TSE disease.

\subsection{Electrophysiological markers and imaging}

Clinical diagnosis of sCJD is often confirmed by the appearance of sharp periodic waves in the patients' electroencephalograms [73, 111]. However, this test is unreliable as a stand-alone diagnostic of vCJD and is impractical for use with ruminants. Magnetic resonance imaging (MRI) has also been applied to the study of patients with variant and sporadic CJD but no consistent diagnostic differences between the experimental groups was observed [28, 107], although the bilateral pulvinar high signal had been shown to be of potential utility in the confirmation of CJD [129]. However, although MRI is non-invasive, it is expensive and impractical to use with animals.

Researchers at the University of Manchester [5, 84, 125] have reported on the development of "Fathom" a commercial, non-invasive ante-mortem test for diagnosis of BSE in live animals and possibly vCJD. The reported technique relies on high-resolution electrocardiography (ECG) which can reveal abnormal heart rate variability (respiratory sinus arrhythmia or RSA) in the early stages of TSE infection. It is thought that RSA is altered during BSE onset by prions from the gut passing along the vagus nerve into the solitary nucleus, an area of the brain that controls RSA [10, 86, 122]. The test has been shown to predict BSE infection in cows eight months prior to onset of clinical symptoms of BSE. The test 
is simple in that an ECG monitor and a simple breathing monitor is fitted to the animal and the full test can be carried out within minutes. More recently, Pomfrett et al. [85] investigated autonomic nervous system activity by analysis of low- and high- frequency heart rate variability (HRV) in control cattle and cattle challenged with either $1 \mathrm{~g}$ or $100 \mathrm{~g}$ of BSE infected material. They reported a significant difference in the level of high-frequency HRV between control cattle and cattle dosed with $1 \mathrm{~g}$ or $100 \mathrm{~g}$ of BSE-infected brain material. Additionally, a significant difference was observed in the low frequency HRV of cattle fed $100 \mathrm{~g}$ of BSE-infected material in comparison to control cattle and cattle fed $1 \mathrm{~g}$ of infected material suggesting that the extent of the perturbation of low frequency HRV was dose related. This study provides further evidence to support the hypothesis that there are significant differences in the HRV between control cattle and BSE infected cattle and this may have implications in the development of a preclinical diagnostic tool for TSE diseases.

Since the body's respiratory system is the first to be attacked during VCJD infection, it was postulated that similar abnormal heart rate variability signatures might be detectable in humans at early stages of vCJD [125]. This work is currently being undertaken by Woolfson et al. [125] who recently reported on the results of Fathom analysis on two patients with clinical symptoms of vCJD and on seven healthy subjects. Preliminary data indicated significant differences in ECG heart rate variability between control and vCJD subjects and new studies are underway with larger subject groups.

\subsection{Metabolite markers}

\subsubsection{Corticosteroids}

Schelcher et al. [103] suggested that neuroendocrine dysfunction caused by TSE in sheep resulted in changes in endogenous metabolites, hormones and enzymes. Pre- vious studies have reported adrenal gland enlargement in ewes with scrapie [8] and in experimentally infected hamsters [20]. Additionally, cortisol secretion is altered in patients suffering from fatal familial insomnia [87]. Based upon these observations Schelcher et al. [103] investigated plasma and urine corticoid concentrations (cortisol, 20 $\beta$-dihydrocortisol and cortisone) in clinical phase scrapie infected ewes. There was a significant increase in plasma and urine corticoid levels in the scrapie ewes compared to the control ewes suggesting disease-associated hypercortisolism [103]. However, these data must be treated with caution as hypercortisolism is often associated with non-TSE animal stresses, although the authors report no signs of stress were observed in the scrapie infected ewes. The authors proposed 20 $\beta$-dihydrocortisol, a primary cortisol metabolite in ewes, as a potential surrogate marker of prion disease. Furthermore, Gayrard et al. [33] reported elevated levels of plasma cortisol in natural scrapie as a result of over-stimulation of the adrenal gland, and suggested that hypercorticism is an endocrine feature of ewes with natural scrapie.

More recently, Picard-Hagen et al. [83] evaluated several plasma corticoids (cortisol, 20ß-dihydrocortisol and cortisone) as markers of scrapie disease. Plasma concentrations of 20 $\beta$-dihydrocortisol and cortisone were disappointing as markers of clinical infection when considered separately (only $42 \%$ and $58 \%$ of infected sheep classified correctly, respectively). However, combination of plasma $20 \beta$-dihydrocortisol and urinary creatinine classified correctly $98 \%$ of healthy sheep and $82 \%$ of scrapie-affected sheep, respectively. The sensitivity and the specificity of cortisol metabolites and urinary creatinine are inadequate when used separately, but when a combination of these analytes was considered the sensitivity and specificity of the markers are more significant. Furthermore, levels of cortisol, 20 $\beta$ dihydrocortisol and cortisone in combination with their relative binding capacities to the corticosteroid binding globulin may prove 
more useful. This latter phenomenon is important as there appears to be an additional scrapie-induced effect on the binding capacity of this protein [83].

\subsubsection{Blood metabolites}

In 2000, Moorby et al. [67] reported on a nutritional study involving dairy cows later diagnosed as having BSE. Blood samples from 47 dairy cows over a 28 -week period were analysed for several standard bovine metabolites and hormones. They reported differences between animals incubating BSE and control cattle at times of nutritional stress, i.e. at the start of lactation, at calving and when the intake of concentrate feed was decreased. The cattle that developed BSE had reduced feed intakes during lactation, increased concentrations of plasma $\beta$-hydroxybutyrate, reduced milk yields and reduced milk fat concentrations in early lactation. Plasma protein concentrations were increased one week before calving and concentrations of urea were significantly decreased five weeks before calving. No differences in concentration of growth hormone (somatotrophin), prolactin, oestradiol $17-\beta$ and progesterone in plasma were observed. These data suggest that the energy metabolism of dairy cows infected with BSE is altered. More recent Moorby et al. [68] have used gas chromatography mass spectrometry (GCMS) to identify TSE associated biochemical changes in metabolites. They reported increased levels of lactic acid at the clinical and preclinical phases in BSE infected dairy cattle. In addition, alanine, leucine, serine and glutamic acid showed altered levels in preclinical BSE cows in comparison to control cattle. Moorby et al. [68] proposed that increased plasma concentrations of alanine and lactic acid and decreased glutamate and serine in cattle sera may have been due to increased anaerobic respiration in BSE-infected cattle. However, these results were not conclusive as only a small number of cattle were tested and changes in amino acid and lactic acid concentrations can be attributed to a number of other conditions. Moorby et al. [68] also investigated plasma fatty acid content in BSE infected and control cattle but no significant differences were observed. Although studies by Moorby et al. [67, 68] were inconclusive, they were made using naturally infected cattle and they do highlight several significant biochemical changes associated with the progression of the disease which may lead to the discovery of more appropriate biomarkers of TSE.

Multiple endocrine alterations have been reported to be common amongst prion and other neurodegenerative diseases $[19,33$, $82,118,128]$. A recent study by Viguié et al. [118] investigated links between scrapie infection and alterations in somatotrophic function; it was reported that infected animals exhibited double the mean growth hormone $(\mathrm{GH})$ concentration during anoestrous and breeding seasons. Furthermore, plasma glucose, insulin and urea concentrations were reported to be higher in scrapie-affected ewes in comparison to controls [118]. This study demonstrates an association between endocrine and metabolic alterations and scrapie disease.

\subsubsection{Mid-infrared spectroscopy}

Recently, Lasch et al. [59] and Schmitt et al. [106] hypothesised that disease specific alterations may be identified by Fourier transform infrared (FTIR) spectroscopy. This technique is a structure sensitive, nondestructive analysis that provides characteristic fingerprint signatures of the vibrational features of the sample matrix. Schmitt et al. [106] reported the use of FTIR spectroscopy with artificial neural network (ANN) data analysis as a diagnostic tool to differentiate between sera from healthy Syrian hamsters and scrapie-infected hamsters [106]. It was reported that this approach is sensitive and specific (97\% and 100\% respectively) but it was not known whether the changes detected by FTIR were specific to TSEs or whether they were due to bacterial, viral, fungal or parasitic micro-organisms. Analysis by FTIR has proved useful for 
discriminating between scrapie and BSE pathological PrP strains [112], identifying protein structural changes in nerve ganglia of infected hamsters [56], and brain tissue of TSE infected animals $[54,55]$.

Lasch et al. [59] have utilised FTIR combined with multivariate pattern recognition analysis to test blood sera of cattle in field studies. In their study, over 800 blood samples from cattle were tested by FTIR including healthy controls, BSE positive, and animals suffering from classical bacterial or viral infections. Analysis of the data achieved a sensitivity and specificity for BSE detection of $96 \%$ and $92 \%$ respectively. These data indicate strongly that BSE causes specific metabolite shifts in blood and support the validity of investigating biomarkers of TSE infection per se. It remains to be shown how early after infection TSEs can be detected by FTIR analysis of sera and what effects age, gender, breed and nutrition all have on the specificity of the test.

\subsection{Transcriptional markers: erythroid differentiation-related factor}

Transcription of the gene encoding erythroid differentiation-related factor (EDRF) was reported to be down-regulated in TSE infected mice, the mRNA therefore providing a novel molecular marker of preclinical TSE disease [64]. Expression of EDRF is predominantly found in erythroid precursors, a cell lineage that researchers would not normally have linked with prion disease $[1,110]$, in tissues of the spleen, bone marrow, whole blood of infected rodents, in bone marrow of BSE-infected cattle and in whole blood of sheep showing clinical symptoms of scrapie infection [64]. The authors have suggested that the erythroidlineage cells may have a role in the pathogenesis of TSE. In further studies EDRF transcription in healthy humans was found to occur with a high degree of variation [36], which questions the suitability of using EDRF mRNA levels as a marker of TSE disease.
More recently, using microarray technology Xiang et al. [126] identified 121 genes from brains of scrapie-infected mice whose expression was at least twice that in control animals. The genes expressed were found to encode proteins involved in several functions including proteolysis, protease inhibition, cell growth and maintenance, immune response and molecular metabolism. Genes for several cathepsins and S100 protein were also evident [126]. The authors reported that elevated gene levels correlated temporarily with the onset of $\mathrm{PrPSc}$ accumulation and the activation of glia, which may have contributed to neuronal cell death [126]. The above studies demonstrate the potential of genes as diagnostic markers of prion disease.

In 2002, Brenig et al. [15] reported on a plasma based anti-mortem test that relies on a specific RNA marker of preclinical BSE. The test involved amplification of specific microviscular RNA species from sera by real time PCR. The levels of these RNAs were then compared to reference standards and if outside the normal range the animal was considered infected. Brenig et al. [15] reported that the TSE test proved $100 \%$ sensitive in a study of 6 BSE infected cows, which were later confirmed as being positive for BSE by a licensed prion test [15]. Additionally, the test was $100 \%$ specific on animals tested from apparently healthy herds. Interestingly, 2 out of the 57 cohort animals analysed were also identified as being BSE positive, indicating the possibility of lateral BSE transfer. However, no further work has since been reported on the TSE diagnostic test. This study highlights the potential to develop biomarkers of disease status based on the biological progression of the disease.

\section{SUMMARY AND FUTURE PERSPECTIVES}

The area of TSE biomarker research is highly active and many of the diagnostic tests currently being developed are described in this review. Most of these tests rely on 
differences in protein expression, metabolite profile or mRNA abundance between healthy and diseased groups. Many of these tests are still at early stages of development but advances in analytical methods will most likely contribute to the development of more sensitive and specific methods that allow the detection of TSE diseases long before clinical signs are apparent. The most promising approaches for pre-clinical diagnosis appear to be those based on protein expression, which may be due to downstream effects of the neurological dysfunction of the animal. Many approaches rely on detecting differences in the brain that are consistent with TSE disease progression and consequently are not as amenable for the testing of live animals. One novel approach is the use of molecular techniques to look for specific transcript profiles in the brain tissues of infected individuals. Other approaches based on metabolomic or proteomic analysis also hold promise for the identification of novel markers which could form the basis for a wide range of preclinical TSE diagnostics in the future that permit testing of blood and urine samples. A wide range of approaches have identified many potential markers of TSE disease but it is evident that further work needs to be conducted before any of these tests can be made available commercially. A primary objective of these further investigations will be to clarify if these markers are specific to TSE disease or whether they are altered in other diseases or disorders. Furthermore, it remains to be demonstrated if metabolite and protein biomarkers are of use at the pre-symptomatic stage as disease indicative levels may only be present at an advanced disease stage. It is also apparent that the development of biomarker tests is frequently hampered by lack of detection method sensitivity and specificity and further advances will also be necessary in this area.

\section{ACKNOWLEDGEMENTS}

The authors would like to thank M.K. Theodorou, R. Jones and A. Winters for helpful comments on the manuscript. The TSE work at the Institute of Grassland and Environmental Research and the Veterinary Laboratories Agency is funded by the UK Food Standards Agency and the Department for Environment, Food and Rural Affairs.

\section{REFERENCES}

[1] Aguzzi A., Blood simple prion diagnostics, Nat. Med. 7 (2001) 289-290.

[2] Aksamit A.J.J., Preissner C.M., Homburger H.A., Quantitation of 14-3-3 and neuron-specific enolase proteins in CSF in CreutzfeldtJakob disease, Neurology 57 (2001) 728-730.

[3] Anderson R.M., Donnelly C.A., Ferguson N.M., Woolhouse M.E.J., Watt C.J., Udy H.J., MaWhinney S., Dunstan S.P., Southwood T.R.E., Wilesmith J.W., Ryan J.B.M., Hoinville L.J., Hillerton J.E., Austin A.R., Wells G.A.H., Transmission dynamics and epidemiology of BSE in British cattle, Nature 382 (1996) 779-788.

[4] Andreoletti O., Berthon P., Marc D., Sarradin P., Grosclaude J., van Keulen L., Schelcher F., Elsen J.M., Lantier F., Early accumulation of $\mathrm{PrPSc}^{\mathrm{S}}$ in gut-associated lymphoid and nervous tissues of susceptible sheep from a Romanov flock with natural scrapie, J. Gen. Virol. 81 (2000) 3115-3126.

[5] Austin A.R., Meek S., Webster S., Pomfrett C.J.D., Heart rate variability in BSE, Vet. Rec. 139 (1996) 631.

[6] Barbuddhe S.B., Malik S.V.S., Choudhary S.P., Gupta L.K., Kinetics of interferongamma production and its comparison with anti-listeriolysin $\mathrm{O}$ detection in experimental bovine listeriosis, Vet. Res. Commun. 22 (1998) 505-516.

[7] Beaudry P., Cohen P., Brandel J.P., DelasnerieLaupretre N., Richard S., Launay J.M., Laplanche J.L., 14-3-3 protein, neuron-specific enolase, and S-100 protein in cerebrospinal fluid of patients with Creutzfeldt-Jakob disease, Dement. Geriatr. Cogn. Disord. 10 (1999) 40-46.

[8] Beck E., Parry H.B., Daniel P.M., Degeneration of cerebellar and hypothalamo-neurohypophysial systems in sheep with scrapie; and its relationship to human system degenerations, Brain 87 (1964) 153-176.

[9] Beekes M., McBride P.A., Early accumulation of pathological PrP in the enteric nervous system and gut-associated lymphoid tissue of hamsters orally infected with scrapie, Neurosci. Lett. 278 (2000) 181-184. 
[10] Beekes M., McBride P.A., Baldauf E., Cerebral targeting indicates vagal spread of infection in hamsters fed with scrapie, J. Gen. Virol. 79 (1998) 601-607.

[11] Beekes M., Otto M., Wiltfang J., Bahn E., Poser S., Baier M., Late increase of serum S100 beta protein levels in hamsters after oral or intraperitoneal infection with scrapie, J. Infect. Dis. 180 (1999) 518-520.

[12] Bellon A., Seyfert-Brandt W., Lang W., Baron H., Groner A., Vey M., Improved conformation-dependent immunoassay: suitability for human prion detection with enhanced sensitivity, J. Gen. Virol. 84 (2003) 19211925.

[13] Bennion B.J., Daggett V., Protein conformation and diagnostic tests: The prion protein, Clin. Chem. 48 (2002) 2105-2114

[14] Bodemer W., Kaup F.J., Comments on present-day spread and epidemiology of BSE and prion diseases, Gesundheitswesen 66 Suppl. 1 (2004) S21-S25.

[15] Brenig B., Schütz E., Urnovitz H., Cellular nucleic acids in serum and plasma as new diagnostic tools, Berl. Munch. Tierarztl. Wochenschr. 115 (2002) 122-124.

[16] Brown P., The phantasmagoric immunology of transmissible spongiform encephalopathy, Res. Publ. Assoc. Res. Nerv. Ment. Dis. 68 (1990) 305-313.

[17] Brown P., Rohwer R.G., Dunstan B.C., MacAuley C., Gajdusek D.C., Drohan W.N., The distribution of infectivity in blood components and plasma derivatives in experimental models of transmissible spongiform encephalopathy, Transfusion 38 (1998) 810-816.

[18] Brown P., Cervenakova L., Diringer H., Blood infectivity and the prospects for a diagnostic screening test in Creutzfeldt-Jakob disease, J. Lab. Clin. Med. 137 (2001) 5-13.

[19] Carp R.I., Kim Y.S., Callahan S.M., Scrapieinduced alterations in glucose-tolerance in mice, J. Gen. Virol. 70 (1989) 827-835.

[20] Carp R.I., Kim Y.S., Callahan S.M., Pancreatic lesions and hypoglycemia-hyperinsulinemia in scrapie-injected hamsters, J. Infect. Dis. 161 (1990) 462-466.

[21] Carrette O., Demalte I., Scherl A., Yalkinoglu O., Corthals G., Burkhard P., Hochstrasser D.F., Sanchez J.C., A panel of cerebrospinal fluid potential biomarkers for the diagnosis of Alzheimer's disease, Proteomics 3 (2003) 1486-1494.

[22] Chandler R.L., Attempts to demonstrate antibodies in scrapie disease, Vet. Rec. 71 (1959) $58-59$.
[23] Choe L.H., Green A., Knight R.S.G., Thompson E.J., Lee K.H., Apolipoprotein E and other cerebrospinal fluid proteins differentiate ante mortem variant Creutzfeldt-Jakob disease from ante mortem sporadic CreutzfeldtJakob disease, Electrophoresis 23 (2002) 2242-2246.

[24] Detwiler L.A., Baylis M., The epidemiology of scrapie, Rev. Sci. Tech. Off. Int. Epizoot. 22 (2003) 121-143.

[25] DiazF., Masso F., Paez A., Varela E., SuarezGuemes F., Montano L.F., Secretion of IFNgamma by bovine peripheral blood mononuclear cells stimulated with Mycobacterium bovis protein fractions obtained by isoelectric-focusing, Vet. Immunol. Immunopathol. 67 (1999) 203-212.

[26] Diedrich J.F., Bendheim P.E., Kim Y.S., Carp R.I., Haase A.T., Scrapie-associated prion protein accumulates in astrocytes during scrapie infection, Proc. Natl. Acad. Sci. USA 88 (1991) 375-379.

[27] Diedrich J.F., Minnigan H., Carp R.I., Whitaker J.N., Race R., Frey W., Haase A.T., Neuropathological changes in scrapie and Alzheimer's disease are associated with increased expression of apolipoprotein-E and cathepsin-D in astrocytes, J. Virol. 65 (1991) 4759-4768.

[28] Finkenstaedt M., Szudra A., Zerr I., Poser S., Hise J.H., Stoebner J.M., Weber T., MR imaging of Creutzfeldt-Jakob disease, Radiology 199 (1996) 793-798.

[29] Foster J.D., Parnham D.W., Hunter N., Bruce M., Distribution of the prion protein in sheep terminally affected with BSE following experimental oral transmission, J. Gen. Virol. 82 (2001) 2319-2326.

[30] Fukuyama R., Izumoto T., Fushiki S., The cerebrospinal fluid level of glial fibrillary acidic protein is increased in cerebrospinal fluid from Alzheimer's disease patients and correlates with severity of dementia, Eur. Neurol. 46 (2001) 35-38.

[31] Furukawa H.,Doh-ura K., Okuwaki R., Shirabe S., Yamamoto K., Udono H., Ito T. Katamine S., Niwa M., A pitfall in diagnosis of human prion diseases using detection of protease-resistant prion protein in urine Contamination with bacterial outer membrane proteins, J. Biol. Chem. 279 (2004) 23661-23667.

[32] Gauczynski S., Peyrin J.M., Haik S., Leucht C., Hundt C., Rieger R., Krasemann S. Deslys J.P., Dormont D., Lasmezas C.I., Weiss S., The 37-kDa/67-kDa laminin receptor acts as the cell-surface receptor for the cellular prion protein, EMBO J. 20 (2001) 5863-5875. 
[33] Gayrard V., Picard-Hagen N., Grino M., Sauze N., Grandjean C., Galea J., Andreoletti O., Schelcher F., Toutain P.L., Major hypercorticism is an endocrine feature of ewes with naturally occurring scrapie, Endocrinology 141 (2000) 988-994.

[34] Ghosh S., Mechanism of intestinal entry of infectious prion protein in the pathogenesis of variant Creutzfeldt-Jakob disease, Adv. Drug Deliv. Rev. 56 (2004) 915-920.

[35] Giles J., Mad cow disease comes to Japan, Nature 413 (2001) 240-240.

[36] GlockB., Winter M., Rennhofer S.O., Brunholzl E., Troscher D., Reisacher R.B.K., Mayr W.R., Transcript level of erythroid differentiation-related factor, a candidate surrogate marker for transmissible spongiform encephalopathy diseases in blood, shows a broad range of variation in healthy individuals, Transfusion 43 (2003) 1706-1710.

[37] Godfroid J., Czaplicki G., Kerkhofs P., Weynants V., Wellemans G., Thiry E., Letesson J.J., Assessment of the cell-mediated immunity in cattle infection after bovine herpesvirus 4 infection, using an in vitro antigen-specific interferon-gamma assay, Vet. Microbiol. 53 (1996) 133-141.

[38] Green A.J.E., Use of 14-3-3 in the diagnosis of Creutzfeldt-Jakob disease, Biochem. Soc. Trans. 30 (2002) 382-386.

[39] Green A.J.E., Jackman R., Marshall T.A., Thompson E.J., Increased S-100b in the cerebrospinal fluid of some cattle with bovine spongiform encephalopathy, Vet. Rec. 145 (1999) 107-109.

[40] Green A.J.E., Thompson E.J., Stewart G.E., Zeidler M., McKenzie J.M., MacLeod M.A., Ironside J.W., Will R.G., Knight R.S.G., Use of 14-3-3 and other brain-specific proteins in CSF in the diagnosis of variant CreutzfeldtJakob disease, J. Neurol. Neurosurg. Psychiatry 70 (2001) 744-748.

[41] Guillaume E., Zimmermann C., Burkhard P.R., Hochstrasser D.F., Sanchez J.C., A potential cerebrospinal fluid and plasmatic marker for the diagnosis of CreutzfeldtJakob disease, Proteomics 3 (2003) 14951499.

[42] Heggebo R., Press C.M., Gunnes G., Lie K.I., Tranulis M.A., Ulvund M., Groschup M.H., Landsverk T., Distribution of prion protein in the ileal Peyer's patch of scrapie-free lambs and lambs naturally and experimentally exposed to the scrapie agent, J. Gen. Virol. 81 (2000) 2327-2337.

[43] Heppner F.L., Arrighi I., Kalinke U., Aguzzi A., Immunity against prions? Trends Mol. Med. 7 (2001) 477-479.
[44] Hochstrasser D.F., Frutiger S., Wilkins M.R., Hughes G., Sanchez J.C., Elevation of apolipoprotein $\mathrm{E}$ in the CSF of cattle affected by BSE, FEBS Lett. 416 (1997) 161-163.

[45] Holtzman D.M., Pitas R.E., Kilbridge J., Nathan B., Mahley R.W., Bu G.J., Schwartz A.L., Low-density-lipoprotein receptor-related protein mediates apolipoprotein E-dependent neurite outgrowth in a central nervous system-derived neuronal cell-line, Proc. Natl. Acad. Sci. USA 92 (1995) 9480-9484.

[46] Horiuchi M., Caughey B., Prion protein interconversions and the transmissible spongiform encephalopathies, Structure Fold. Des. 7 (1999) R231-R240.

[47] Houston F., Foster J.D., Chong A., Hunter N., Bostock C.J., Transmission of BSE by blood transfusion in sheep, Lancet 356 (2000) 9991000.

[48] Hundt C., Peyrin J.M., Haik S., Gauczynski S., Leucht C., Rieger R., Riley M.L., Deslys J.P., Dormont D., Lasmezas C.I., Weiss S., Identification of interaction domains of the prion protein with its $37-\mathrm{kDa} / 67-\mathrm{kDa}$ laminin receptor, EMBO J. 20 (2001) 58765886.

[49] Hunter N., Foster J., Chong A., McCutcheon S., Parnham D., Eaton S., MacKenzie C., Houston F., Transmission of prion diseases by blood transfusion, J. Gen. Virol. 83 (2002) 2897-2905.

[50] Ironside J.W., Head M.W., Variant Creutzfeldt-Jakob disease: risk of transmission by blood and blood products, Haemophilia 10 (2004) 64-69.

[51] Itoh N., Arai H., Urakami K., Ishiguro K., Ohno H., Hampel H., Buerger K., Wiltfang J., Otto M., Kretzschmar H., Moeller H.J., Imagawa M., Kohno H., Nakashima K., Kuzuhara S., Sasaki H., Imahori K., Largescale, multicenter study of cerebrospinal fluid tau protein phosphorylated at serine 199 for the antemortem diagnosis of Alzheimer's disease, Ann. Neurol. 50 (2001) 150-156.

[52] Jones V., Martin T.C., Keyes P., Dawson M., Protein markers in cerebrospinal fluid from BSE-affected cattle, Vet. Rec. 139 (1996) 360-363.

[53] Kellar J.A., Lees V.W., Risk management of the transmissible spongiform encephalopathies in North America, Rev. Sci. Tech. Off. Int. Epizoot. 22 (2003) 201-225.

[54] Kneipp J., Lasch P., Baldauf E., Beekes M., Naumann D., Detection of pathological molecular alterations in scrapie- infected hamster brain by Fourier transform infrared (FT-IR) spectroscopy, Biochim. Biophys. Acta 1501 (2000) 189-199. 
[55] Kneipp J., Beekes M., Lasch P., Naumann D., Molecular changes of preclinical scrapie can be detected by infrared spectroscopy, J. Neurosci. 22 (2002) 2989-2997.

[56] Kneipp J., Miller L.M., Joncic M., Kittel M., Lasch P., Beekes M., Naumann D., In situ identification of protein structural changes in prion-infected tissue, Biochim. Biophys. Acta 1639 (2003) 152-158.

[57] Kordek R., Liberski P.P., Yanagihara R., Isaacson S., Gajdusek D.C., Molecular analysis of prion protein $(\mathrm{PrP})$ and glial fibrillary acidic protein (GFAP) transcripts in experimental Creutzfeldt-Jakob disease in mice, Acta Neurobiol. Exp. 57 (1997) 85-90.

[58] Kubler E., Oesch B., Alex J.R., Diagnosis of prion diseases, Br. Med. Bull. 66 (2003) 267-279.

[59] Lasch P., Schmitt J., Beekes M., Udelhoven T., Eiden M., Fabian H., Petrich W., Naumann D., Antemortem identification of bovine spongiform encephalopathy from serum using infrared spectroscopy, Anal. Chem. 75 (2003) 6673-6678.

[60] Lazarini F., Castelnau P., Chermann J.F., Deslys J.P., Dormont D., Modulation of prion protein gene-expression by growthfactors in cultured mouse astrocytes and Pc12 Cells, Mol. Brain Res. 22 (1994) 268-274.

[61] Lee K.H., Harrington M.G., 14-3-3 and BSE, Vet. Rec. 140 (1997) 206-207.

[62] McBride P.A., Beekes M., Pathological PrP is abundant in sympathetic and sensory ganglia of hamsters fed with scrapie, Neurosci. Lett. 265 (1999) 135-138.

[63] McBride P.A., Schulz-Schaeffer W.J., Donaldson M., Bruce M., Diringer H., Kretzschmar H.A., Beekes M., Early spread of scrapie from the gastrointestinal tract to the central nervous system involves autonomic fibers of the splanchnic and vagus nerves, J. Virol. 75 (2001) 9320-9327.

[64] Miele G., Manson J., Clinton M., A novel erythroid-specific marker of transmissible spongiform encephalopathies, Nat. Med. 7 (2001) 361-364.

[65] Minghetti L., Greco A., Cardone F., Puopolo M., Ladogana A., Almonti S., Cunningham C., Perry V.H., Pocchiari M., Levi G., Increased brain synthesis of prostaglandin E-2 and F-2isoprostane in human and experimental transmissible spongiform encephalopathies, J. Neuropathol. Exp. Neurol. 59 (2000) 866871.

[66] Missler U., Wiesmann M., Wittmann G., Magerkurth O., Hagenstrom H., Measurement of glial fibrillary acidic protein in human blood: Analytical method and prelim- inary clinical results, Clin. Chem. 45 (1999) 138-141.

[67] Moorby J.M., Dhanoa M.S., Austin A.R., Aspects of the metabolism of dairy cows during the incubation of bovine spongiform encephalopathy, Vet. Rec. 147 (2000) 409-412.

[68] Moorby J.M., Begley P., Nash R.J., Theodorou M.K., Austin A.R., Plasma metabolites indicate energy metabolism disruption during the preclinical phase of bovine spongiform encephalopathy infection, Res. Vet. Sci. 73 (2002) 191-193.

[69] Moynagh J., Schimmel H., Tests for BSE evaluated, Nature 400 (1999) 105-105.

[70] Murphy C., Breen C., Rogers M., Giese M., Interferon gamma and prostaglandin in BSEinfected cattle, Cytokine 13 (2001) 169-173.

[71] Neill S.D., Cassidy J., Hanna J., Mackie D.P., Pollock J.M., Clements A., Walton E., Bryson D.G., Detection of Mycobacterium bovis infection in skin test-negative cattle with an assay for bovine interferon-gamma, Vet. Rec. 135 (1994) 134-135.

[72] Nunnally B.K., It's a mad, mad, mad, mad cow: a review of analytical methodology for detecting BSE /TSE, Trends Analyt. Chem. 21 (2002) 82-89.

[73] Otto M., Wiltfang J., Differential diagnosis of neurodegenerative diseases with special emphasis on Creutzfeldt-Jakob disease, Restor. Neurol. Neurosci. 21 (2003) 191-209.

[74] Otto M., Stein H., Szudra A., Zerr I., Bodemer M., Gefeller O., Poser S., Kretzschmar H.A., Mader M., Weber T. S-100 protein concentration in the cerebrospinal fluid of patients with Creutzfeldt-Jakob disease, J. Neurol. 244 (1997) 566-570.

[75] Otto M., Wiltfang J., Tumani H., Zerr I., Lantsch M., Kornhuber J., Weber T., Kretzschmar H.A., Poser S., Elevated levels of tau-protein in cerebrospinal fluid of patients with Creutzfeldt-Jakob disease, Neurosci. Lett. 225 (1997) 210-212.

[76] Otto M., Beekes M., Wiltfang J., Bahn E., Poser S., Diringer H., Elevated levels of serum S100 beta protein in scrapie hamsters, J. Neurovirol. 4 (1998) 572-573.

[77] Otto M., Wiltfang J., Schutz E., Zerr I., Otto A., Pfahlberg A., Gefeller O., Uhr M., Giese A., Weber T., Kretzschmar H.A., Poser S., Diagnosis of Creutzfeldt-Jakob disease by measurement of S100 protein in serum: prospective case-control study, BMJ 316 (1998) 577-582.

[78] Otto M., Wiltfang J., Cepek L., Neumann M., Mollenhauer B., Steinacker P., Ciesielezyk B., Schulz-Schaeffer W., Kretzschmar H.A., 
Poser S., Tau protein and 14-3-3 protein in the differential diagnosis of CreutzfeldtJakob disease, Neurology 58 (2002) 192-197.

[79] Pan K.M., Baldwin M., Nguyen J., Gasset M., Serban A., Groth D., Mehlhorn I., Huang Z.W., Fletterick R.J., Cohen F.E., Prusiner S.B., Conversion of alpha-helices into betasheets features in the formation of the scrapie prion proteins, Proc. Natl. Acad. Sci. USA 90 (1993) 10962-10966.

[80] Parnigotto P.P., Conconi M.T., Effects of prostaglandin E-2 on growth, morphology, morphometry and keratin pattern of bovine corneal epithelial cells cultured in vitro, Anat. Anz. 180 (1998) 511-518.

[81] Peden A.H., Head M.W., Ritchie D.L., Bell J.E., Ironside J.W., Preclinical vCJD after blood transfusion in a PRNP codon 129 heterozygous patient, Lancet 364 (2004) 527-529.

[82] Picard-Hagen N., Gayrard V., Andreoletti O., Galea J., Grandjean C., Mandon-Maurice F., Cabanie P., Schelcher F., Toutain P.L., Melatonin and prolactin secretion profile in naturally occurring scrapie in ewe, J. Pineal Res. 24 (1998) 117-122.

[83] Picard-Hagen N., Gayrard V., Laroute V., Grandjean C., Andreoletti O., Elsen J.M., Schelcher F., Toutain P.L., Discriminant value of blood and urinary corticoids for the diagnosis of scrapie in live sheep, Vet. Rec. 150 (2002) 680-684.

[84] Pomfrett C.J.D., Austin A.R., Bovine spongiform encephalopathy (BSE) disrupts heart rate variability (HRV), J. Physiol. London 501P (1997) P69-P69.

[85] Pomfrett C.J.D., Glover D.G., Bollen B.G., Pollard B.J., Perturbation of heart rate variability in cattle fed BSE- infected material, Vet. Rec. 154 (2004) 687-691.

[86 Porges S.W., Orienting in a defensive world - mammalian modifications of our evolutionary heritage - a Polyvagal theory, Psychophysiology 32 (1995) 301-318.

[87] Portaluppi F., Cortelli P., Avoni P., Vergnani L., Contin M., Maltoni P., Pavani A., Sforza E., Uberti E.C.D., Gambetti P., Lugaresi E., Diurnal blood-pressure variation and hormonal correlates in Fatal Familial Insomnia, Hypertension 23 (1994) 569-576.

[88] Prusiner S.B., Molecular Biology of Prion Diseases, Science 252 (1991) 1515-1522.

[89] Prusiner S.B., Prion diseases and the BSE crisis, Science 278 (1997) 245-251.

[90] Prusiner S.B., The prion diseases, Brain Pathol. 8 (1998) 499-513.

[91] Raabe A., Grolms C., Seifert V., Serum markers of brain damage and outcome pre- diction in patients after severe head injury, Br. J. Neurosurg. 13 (1999) 56-59.

[92] Rieger R.E.F., Lasmezas C.I., Weiss S., The human 37-kDa laminin receptor precursor interacts with the prion protein in eukaryotic cells, Nat. Med. 3 (1997) 1383-1388.

[93] Riemer C., Queck I., Simon D., Kurth R., Baier M., Identification of upregulated genes in scrapie-infected brain tissue, J. Virol. 74 (2000) 10245-10248.

[94] Riond J.L., Hartmann P., Joller-Jemelka H.I., Braun U., S-100 and bovine spongiform encephalopathy, Vet. Rec. 145 (1999) 114-115.

[95] Robey W.G., Jackson R., Walters R.L., Brackett J.M., Harrington C.A., Killian W.R., Use of cerebrospinal fluid levels of 143-3 in predicting neurodegeneration in confirmed BSE symptomatic cattle, Vet. Rec. 143 (1998) 50-51.

[96] Roesler J., Kofink B., Wendisch J., Heyden S., Paul D., Friedrich W., Casanova J.L., Leupold W., Gahr M., Rosen-Wolff A., Listeria monocytogenes and recurrent mycobacterial infections in a child with complete interferon-gamma-receptor (IFN gamma R1) deficiency: Mutational analysis and evaluation of therapeutic options, Exp. Hematol. 27 (1999) 1368-1374.

[97] Ruth L., The quest for new prion tests, Anal. Chem. 75 (2003) 32A-36A.

[98] Safar J.G., Scott M., Monaghan J., Deering C., Didorenko S., Vergara J., Ball H., Legname G., Leclerc E., Solforosi L., Serban H., Groth D., Burton D.R., Prusiner S.B., Williamson R.A., Measuring prions causing bovine spongiform encephalopathy or chronic wasting disease by immunoassays and transgenic mice, Nat. Biotechnol. 20 (2002) 1147-1150.

[99] Sanchez J.C., Guillaume E., Lescuyer P., Allard L., Carrette O., Scherl A., Burgess J., Corthals G.L., Burkhard P.R., Hochstrasser D.F., Cystatin $\mathrm{C}$ as a potential cerebrospinal fluid marker for the diagnosis of CreutzfeldtJakob disease, Proteomics 4 (2004) 22292233.

[100] Sayer N.M., Cubin M., Rhie A., Bullock M., Tahiri-Alaoui A., James W., Structural determinants of conformationally selective, prionbinding aptamers, J. Biol. Chem. 279 (2004) 13102-13109.

[101] Schaller O., Fatzer R., Stack M., Clark J., Cooley W., Biffiger K., Egli S., Doherr M., Vandevelde M., Heim D., Oesch B., Moser M., Validation of a Western immunoblotting procedure for bovine $\mathrm{PrP}^{\mathrm{Sc}}$ detection and its use as a rapid surveillance method for the diagnosis of bovine spongiform encephalopathy (BSE), Acta Neuropathol. 98 (1999) 437-443. 
[102] Schein C.H., Haugg M., Benner S.A., Interferon-gamma activates the cleavage of double-stranded-RNA by bovine seminal ribonuclease, FEBS Lett. 270 (1990) 229-232.

[103] Schelcher F., Picard-Hagen N., Laroute V., Gayrard V.,Popot M.A., Andreoletti O., Toutain P.L., Corticoid concentrations are increased in the plasma and urine of ewes with naturally occurring scrapie, Endocrinology 140 (1999) 2422-2425.

[104] Schiermeier Q., Testing times for BSE, Nature 409 (2001) 658-659.

[105] Schmerr M.J., Jenny A.L., Bulgin M.S., Miller J.M., Hamir A.N., Cutlip R.C., Goodwin K.R., Use of capillary electrophoresis and fluorescent labeled peptides to detect the abnormal prion protein in the blood of animals that are infected with a transmissible spongiform encephalopathy, J. Chromatogr. A 853 (1999) 207-214.

[106] Schmitt J., Beekes M., Brauer A., Udelhoven T., Lasch P., Naumann D., Identification of scrapie infection from blood serum by Fourier transform infrared spectroscopy, Anal. Chem. 74 (2002) 3865-3868.

[107] Schroter A., Zerr I., Henkel K., Tschampa H.J., Finkenstaedt M., Poser S., Magnetic resonance imaging in the clinical diagnosis of Creutzfeldt-Jakob disease, Arch. Neurol. 57 (2000) 1751-1757.

[108] Shaked G.M., Shaked Y., Kariv-Inbal Z., Halimi M., Avraham I., Gabizon R., A protease-resistant prion protein isoform is present in urine of animals and humans affected with prion diseases, J. Biol. Chem. 276 (2001) 31479-31482.

[109] Sigurdson C.J., Spraker T.R., Miller M.W., Oesch B., Hoover E.A., PrPCWD in the myenteric plexus, vagosympathetic trunk and endocrine glands of deer with chronic wasting disease, J. Gen. Virol. 82 (2001) $2327-$ 2334.

[110] Sjögren M., EDRF transcripts and diagnosis of variant Creutzfeldt-Jakob disease, Lancet 357 (2001) 2069-2070

[111] Steinhoff B.J., Racker S., Herrendorf G., Poser S., Grosche S., Zerr I., Kretzschmar H., Weber T., Accuracy and reliability of periodic sharp wave complexes in Creutzfeldt-Jakob disease, Arch. Neurol. 53 (1996) 162-166.

[112] Thomzig A.S.S., Friedrich M., Naumann D., Beekes M., Discriminating scrapie and bovine spongiform encephalopathy isolates by infrared spectroscopy of pathological prion protein, J. Biol. Chem. 279 (2004) 33847-33854

[113] Tyler J.W., Lakritz J., Weaver D., Johnson G., VanMetre D., Smith K., Taylor W., Jenny A., The 14-3-3 cerebrospinal fluid immu- noassay lacks utility in the diagnosis of clinical scrapie, J. Vet. Diagn. Invest. 13 (2001) 537-539.

[114] Van Everbroeck B., Green A.J.E., Vanmechelen E., Vanderstichele H., Pals P., Sanchez-Valle R., Corrales N.C., Martin J.J., Cras P., Phosphorylated tau in cerebrospinal fluid as a marker for Creutzfeldt-Jakob disease, J. Neurol. Neurosurg. Psychiatry 73 (2002) 79-81.

[115] Van Keulen L.J., Schreuder B.E., Vromans M.E., Langeveld J.P., Smits M.A., Pathogenesis of natural scrapie in sheep, Arch. Virol. Suppl. 16 (2000) 57-71.

[116] Van Keulen L.J.M., Vromans M.E.W., Van Zijderveld F.G., Early and late pathogenesis of natural scrapie infection in sheep, APMIS 110 (2002) 23-32.

[117] Verbeek M.M., de Jong D., Kremer H.P.H., Brain-specific proteins in cerebrospinal fluid for the diagnosis of neurodegenerative diseases, Ann. Clin. Biochem. 40 (2003) 25-40.

[118] Viguié C., Chilliard Y., Gayrard V., PicardHagen N., Monget P., Dutour A., Toutain P.L., Alterations of somatotropic function in prion disease in sheep, J. Endocrinol. 183 (2004) 427-435.

[119] Völkel D., Zimmermann K., Zerr I., Bodemer M., Lindner T., Turecek P.L., Poser S., Schwarz H.P., Immunochemical determination of cellular prion protein in plasma from healthy subjects and patients with sporadic CJD or other neurologic diseases, Transfusion 41 (2001) 441-448.

[120] Völkel D., Zimmermann K., Zerr I., Lindner T., Bodemer M., Poser S., Schwarz H.P., Creactive protein and IL-6: new marker proteins for the diagnosis of CJD in plasma? Transfusion 41 (2001) 1509-1514.

[121] Wedlock D.N., Aldwell F.E., Collins D.M., de Lisle G.W., Wilson T., Buddle B.M., Immune responses induced in cattle by virulent and attenuated Mycobacterium bovis strains: Correlation of delayed-type hypersensitivity with ability of strains to grow in macrophages, Infect. Immun. 67 (1999) 2172-2177.

[122] Wells G.A.H., Hancock R.D., Cooley W.A., Richards M.S., Higgins R.J., David G.P., Bovine spongiform encephalopathy - diagnostic-significance of vacuolar changes in selected nuclei of the medulla-oblongata, Vet. Rec. 125 (1989) 521-524.

[123] Will R.G., Ironside J.W., Zeidler M., Cousens S.N., Estibeiro K., Alperovitch A., Poser S., Pocchiari M., Hofman A., Smith P.G., A new variant of Creutzfeldt-Jakob disease in the UK, Lancet 347 (1996) 921-925. 
[124] Wille H., Michelitsch M.D., Guenebaut V., Supattapone S., Serban A., Cohen F.E., Agard D.A., Prusiner S.B., Structural studies of the scrapie prion protein by electron crystallography, Proc. Natl. Acad. Sci. USA 99 (2002) 3563-3568.

[125] Woolfson L.A.M., Glover D.G., Pollard B.J., Pomfrett C.J.D., Symptomatic vCJD alters heart rate variability, J. Physiol. 551P (2003) C47.

[126] Xiang W., Windl O., Wünsch G., Dugas M., Kohlmann A., Dierkes N., Westner I.M., Kretzschmar H.A., Identification of differentially expressed genes in scrapie- infected mouse brains by using global gene expression technology, J. Virol. 78 (2004) 1105111060 .
[127] Yamada M., Cerebral amyloid angiopathy: An overview, Neuropathology 20 (2000) 8-22.

[128] Ye X., Carp R.I., Histopathological changes in the pituitary glands of female hamsters infected with the $139 \mathrm{H}$ strain of scrapie, J. Comp. Pathol. 114 (1996) 291-304.

[129]Zeidler M., Sellar R.J., Collie D.A., Knight R., Stewart G., Macleod M.A., Ironside J.W., Cousens S., Colchester A.F.C., Hadley D.M., Will R.G., The pulvinar sign on magnetic resonance imaging in variant Creutzfeldt-Jakob disease, Lancet 355 (2000) 1412-1418.

[130] Zerr I., Bodemer M., Racker S., Grosche S., Poser S., Kretzschmar H.A., Weber T., Cerebrospinal-fluid concentration of neuron-specific enolase in diagnosis of Creutzfeldt-Jakob disease, Lancet 345 (1995) 1609-1610. 